\title{
On the systematics of the tribe Tanytarsini (Diptera: Chironomidae) - three new species from Finland
}

\author{
Wojciech Gilka \& Lauri Paasivirta
}

Giłka, W. \& Paasivirta, L. 2008: On the systematics of the tribe Tanytarsini (Diptera: Chironomidae) - three new species from Finland. - Entomol. Fennica 19: $41-48$.

Three new chironomid species of the tribe Tanytarsini are described from Finland: Micropsectra malla sp. n., Paratanytarsus paralaccophilus sp. n. and Tanytarsus paraniger $\mathrm{sp}$. $\mathrm{n}$. The new species are compared with their closest relatives and their systematic position is discussed. As a result of our study, the Micropsectra recurvata species group Säwedal, 1981 is regarded as unwarranted and its species are included to the Micropsectra notescens group Säwedal, 1976. The Finnish fauna of the tribe Tanytarsini, consisting of 123 valid species, is one of the most species-rich in Europe.

W. Gilka, Department of Invertebrate Zoology, University of Gdansk, Al. Marszalka Pitsudskiego 46,81-378 Gdynia, Poland; E-mail: scorpio@ocean. univ.gda.pl

L. Paasivirta, Ruuhikoskenkatu 17 B 5, 24240 Salo, Finland; E-mail: lauri. paasivirta@suomi24.fi

Received 9 February 2007, accepted 5 June 2007

\section{Introduction}

Chironomids of the tribe Tanytarsini, due to the larval habitat preferences, are particularly species-rich in most lacustrine regions of the world. Although the Fennoscandian fauna of the tribe is one of the best known, it still yields species new to science (Giłka 2005, Giłka \& Paasivirta 2007). Recent studies indicate that the Finnish Tanytarsini comprise at least 120 species (Paasivirta, unpubl.), i.e. nearly $70 \%$ of the European fauna (Sæther \& Spies 2004, Giłka \& Abramczuk 2006, Stur \& Ekrem 2006).

This paper contains descriptions of three further new species found in Finland. Micropsectra malla sp. n. of the notescens group Säwedal, 1976 is the 20th Finnish and the 37th European
Micropsectra. The new species shows a distinct similarity to Micropsectra tori Säwedal, 1981, so far considered to be a member of the recurvata group Säwedal, 1981. Paratanytarsus paralaccophilus sp. n. (the 16th Finnish and the 19th European Paratanytarsus) forms a distinct species group together with Paratanytarsus laccophilus (Edwards, 1929), its closest and only known group-relative (Reiss \& Säwedal 1981, Cranston et al. 1989). Tanytarsus niger Andersen, 1937 and Tanytarsus paraniger sp. n. (the 9th Finnish and the 10th European species of the norvegicus group) are undoubtedly sibling species, they are, however, easily distinguishable by some unique morphological features found in the new species. 
Table 1. Length $(\mu \mathrm{m})$ of leg segments and leg ratios of male Micropsectra malla sp. $\mathrm{n}$.

\begin{tabular}{lllllllll}
\hline & $\mathrm{fe}$ & $\mathrm{ti}$ & $\mathrm{ta}_{1}$ & $\mathrm{ta}_{2}$ & $\mathrm{ta}_{3}$ & $\mathrm{ta}_{4}$ & $\mathrm{ta}_{5}$ & $\mathrm{LR}$ \\
\hline $\mathrm{p}_{1}$ & $685-755$ & $505-590$ & 645 & 355 & 255 & 175 & 105 & 1.26 \\
& $(720, \mathrm{n}=7)$ & $(545, \mathrm{n}=7)$ & $\mathrm{n}=1$ & $\mathrm{n}=1$ & $\mathrm{n}=1$ & $\mathrm{n}=1$ & $\mathrm{n}=1$ & $\mathrm{n}=1$ \\
$\mathrm{p}_{2}$ & $670-750$ & $590-675$ & $300-345$ & $175-200$ & $125-145$ & $90-95$ & $75-90$ & 0.51 \\
& $(705, \mathrm{n}=7)$ & $(620, \mathrm{n}=7)$ & $(320, \mathrm{n}=4)$ & $(185, \mathrm{n}=4)$ & $(135, \mathrm{n}=4)$ & $(90, \mathrm{n}=4)$ & $(80, \mathrm{n}=4)$ & $(0.51, \mathrm{n}=4)$ \\
$\mathrm{p}_{3}$ & $795-890$ & $750-845$ & $485-535$ & $280-315$ & $230-245$ & $130-145$ & $95-105$ & $0.61-0.63$ \\
& $(840, \mathrm{n}=7)$ & $(785, \mathrm{n}=7)$ & $(505, \mathrm{n}=3)$ & $(295, \mathrm{n}=3)$ & $(235, \mathrm{n}=3)$ & $(140, \mathrm{n}=3)$ & $(100, \mathrm{n}=3)(0.62, \mathrm{n}=3)$ \\
\hline
\end{tabular}

\section{Material and methods}

The material examined was collected in Finland with a sweep net, Malaise- and emergence traps. The specimens caught were dissected and mounted in Canada balsam or Euparal on microscope slides. The wing was measured from the arculus to the tip; lengths of leg segments, spurs and combs were rounded off to the nearest $5 \mu \mathrm{m}$; palpomeres II-V were measured to nearest $1 \mu \mathrm{m}$; antennal and leg ratios (AR and LR, respectively) were rounded off to 0.01 . When 3 or more specimens were measured, the dimensions are reported as ranges followed by the mean (in parentheses). The morphological terminology and abbreviations follow Sæther (1980). The types designated were deposited at the Department of Invertebrate Zoology, University of Gdańsk, Gdynia (DIZUG) and in the Museum and Institute of Zoology of the Polish Academy of Sciences, Warszawa (MIZPAS), Poland.

\section{Results}

\subsection{Micropsectra malla sp. $\mathrm{n}$.}

\subsubsection{Diagnosis}

Adult male. AR 0.61-0.73 (0.67). Gonostylus slender, tapering to tip. Anal point slender with pointed tip or broadened in distal part and apically blunt. Superior volsella finger-shaped. Digitus long and stout, extending beyond apex of superior volsella. Stem of median volsella long, slightly curved and directed laterally, bearing large spoon-shaped lamellae. Inferior volsella stout and short, broadened in median part, with rounded apex.

\subsubsection{Description}

Adult male ( $\mathrm{n}=10$, unless otherwise stated). Wing length $1.61-1.81 \mathrm{~mm}(1.69, \mathrm{n}=7)$. Coloration. Pedicel, tentorium, scutal stripes, postnotum and sternum dark brown; antennal flagellum, scutellum, background of thorax, legs and abdomen greenish-brown; halter and wing pale. Head. Antenna with 13 flagellomeres; AR $0.61-0.73(0.67, \mathrm{n}=5)$; frontal tubercles absent or represented only by small swellings of integument; length of palpomeres II-V $(\mu \mathrm{m}, \mathrm{n}=6): 40$ 48 (44), 95-110 (104), 111-135 (120), 167-171 (169); clypeus with 9-15 setae. Thorax chaetotaxy: Ac 15-20, Dc 9-10, Pa 2-3 (usually 2), Scts 8-10 (usually 8 setae placed in regular row). Wing. Membrane covered with macrotrichia in distal $1 / 2$, dense macrotrichia in cells $r_{4+5}, m_{1+2}$, $\mathrm{m}_{3+4}$ and under veins $\mathrm{Cu}_{1}$ and $\mathrm{An}$; veins $\mathrm{Sc}, \mathrm{M}$, $\mathrm{RM}$, proximal half of $\mathrm{Cu}$ and short proximal section of $\mathrm{R}_{4+5}$ and $\mathrm{M}_{1+2}$ bare, other veins with dense macrotrichia; $R_{4+5}$ ending slightly distal of $M_{3+4}$ and well proximal of $\mathrm{M}_{1+2}$, FCu ending distal of RM. Legs. Fore tibia with straight spur c. 10-15 $\mu \mathrm{m}$ long; combs of mid and hind tibiae fused, teeth c. $10 \mu \mathrm{m}$ (mid tibia) to 10-15 $\mu \mathrm{m}$ long (hind tibia), spurs absent; ta $a_{1}$ of $p_{2}$ bearing 1-2 hookshaped sensilla chaetica $(n=4)$; length of leg segments and leg ratios in Table 1.

Hypopygium. Gonostylus 130-165 $\mu \mathrm{m}$ long, regularly tapering to slender tip. Anal tergite with 1-5 median setae and bands of V-type fused on elevated hump at base of anal point; lateral teeth simple; anal point moderately long, regularly tapering to pointed tip or slightly broadened in distal part and apically blunt, crests separated, 2-4 lateral setae on each side of anal point (Fig. 1a-b). Superior volsella finger-shaped, with apex rounded and directed medially, armed with 2-3 


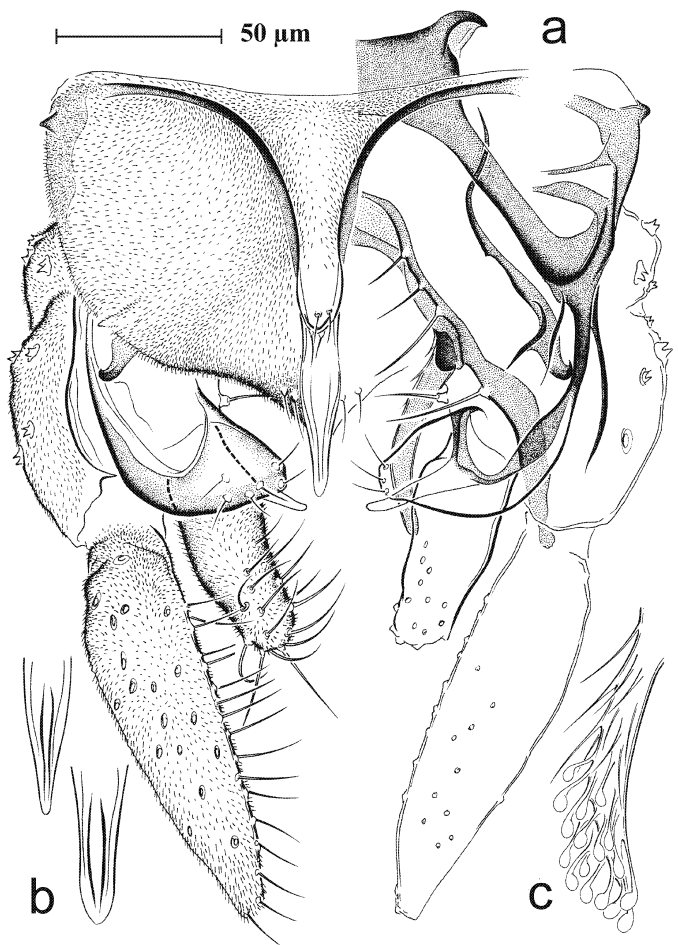

Fig. 1. Micropsectra malla sp. n., male. - a. Hypopygium. - b. Variation in anal point. - c. Median volsella.

apical and 4-7 dorsal setae; digitus well developed, long, extending beyond apex of superior volsella; long Micropsectra-seta on a tall tubercle present (Fig. 1a). Stem of median volsella 60-65 $\mu \mathrm{m}$ long, slightly curved and directed laterally, bearing c. 15-20 big spoon-shaped lamellae (Fig. 1c). Inferior volsella stout but relatively short, broadened in median part, tapering to rounded apex, armed with long setae in distal third (Fig. 1a).

\subsubsection{Type material}

Holotype. Male slide-mounted in Canada balsam: Finland, Inari distr., Sarmitunturi nr. Vanhapää, c. $13 \mathrm{~km}$ west of the Russian border (684'N 28²2'E), 3.VI.-27.VIII.2004, Malaise trap, leg. J. Salmela (DIZUG). Paratypes. 6 $\widehat{\partial} \widehat{\partial}$ : as holotype (4 DIZUG, 2 MIZPAS); 3 $\hat{\sigma}$ : Kilpisjärvi, Kitsi river in Malla Mts. (69 $04^{\prime} \mathrm{N}$ $\left.20^{\circ} 40^{\prime} \mathrm{E}\right), 25$. VI.2004, netting, leg. J. Salmela (DIZUG).

\subsubsection{Derivation of the name}

After the name of Malla hills near Kilpisjärvi where the species was collected for the first time. The name should be treated as a noun in apposition.

\subsubsection{Discussion}

The species morphologically most similar to Micropsectra malla is M. junci (Meigen, 1818) and M. apposita (Walker, 1856), both redescribed by Säwedal (1976) in the notescens group, and in particular Micropsectra tori, originally included to the recurvata group (Säwedal 1981). The combination of a relatively small body size, a low AR, a slender gonostylus and an elongated and laterally curved stem of the median volsella bearing large spoons found in $M$. malla separates the new species from its relatives. Because of the peculiar, stout and short inferior volsella, broadened in its median part, $M$. malla cannot be mistaken for any other species of the genus.

Systematic relationships within the notescens, atrofasciata and attenuata groups of the genus Micropsectra Kieffer have recently been discussed in the literature (Giłka 2001, Giłka \& Abramczuk 2006, Stur \& Ekrem 2006). The male of Micropsectra malla, with its finger-shaped superior volsella and the long digitus of its hypopygium fits the notescens group well. In addition, its long, slender, apically pointed and often slightly tapering in the median part anal point resembles the anal points of the adult males of other species in this group (Fig. 1a, b). The males of $M$. malla also show an elongated and sometimes slightly curved stem of the median volsella (Fig. 1c). This combination of characters fit those proposed for adult males of the recurvata group as well (Säwedal 1981). Thus, M. malla shows affinity both to the species previously assigned to the recurvata group (Säwedal 1981) and to the species of the notescens group (Säwedal 1976, Giłka 2001). Consequently, we see no reason for the notescens group to be split, and we suggest that the notescens and the recurvata groups should be treated as one. The only distinct diagnostic morphological character for the notescens group is the finger-shaped superior volsella, as 
Table 2. Length $(\mu \mathrm{m})$ of leg segments and leg ratios of male Paratanytarsus paralaccophilus sp. $\mathrm{n}$.

\begin{tabular}{|c|c|c|c|c|c|c|c|}
\hline fe & $\mathrm{ti}$ & $\mathrm{ta}_{1}$ & $\mathrm{ta}_{2}$ & $\mathrm{ta}_{3}$ & $\mathrm{ta}_{4}$ & $\mathrm{ta}_{5}$ & LR \\
\hline 660 & 465 & 670 & 365 & 295 & 215 & 95 & 1.44 \\
\hline 660 & 550 & 310 & 185 & 145 & 95 & 75 & 0.56 \\
\hline 770 & 715 & 480 & 315 & 245 & 145 & 90 & 0.67 \\
\hline
\end{tabular}

opposed to the circular superior volsella in the atrofasciata group, and the triangular superior volsella tapering to its pointed apex in the attenuata group.

Adult males of Micropsectra malla were collected at mountain brooks in Finnish Lapland. Seasonal variability in the species' distribution is not known in detail, as M. malla was sampled using the sweep net in late June (spring in the area) and with the Malaise trap during the prolonged period spanning June and August.

\subsection{Paratanytarsus paralaccophilus sp. $\mathrm{n}$.}

\subsubsection{Diagnosis}

Adult male. Gonostylus regularly tapering to slender tip. Superior volsella oval, slightly elongated and medially directed. Digitus slender and sharply pointed. Stem of median volsella long, bearing dense setiform and slender subuliform lamellae. Inferior volsella straight and stout, with bilobed apex bearing elongated protuberance.

\subsubsection{Description}

Adult male $(\mathrm{n}=1-3)$. Wing length $1.51 \mathrm{~mm}$. Coloration. Pedicel, tentorium, scutal stripes, postnotum and sternum dark brown; antennal flagellum and scutellum brown; background of thorax, halter, legs and abdomen olive-brown. Head. Antenna with 13 flagellomeres; AR $0.90(n=1)$; frontal tubercles small, 5-6 $\mu \mathrm{m}$ long; length of palpomeres II-V $(\mu \mathrm{m}, \mathrm{n}=1): 36,87,95$, -; clypeus with 16 setae. Thorax chaetotaxy. Ac 12, De 7, Pa 1, Scts 6 (placed in regular row). Wing. Membrane covered with macrotrichia in distal $1 / 2$, dense macrotrichia in cells $\mathrm{r}_{4+5}, \mathrm{~m}_{1+2}$ and $\mathrm{m}_{3+4}$, a few macrotrichia under vein $\mathrm{Cu}_{1}$; veins $\mathrm{Sc}, \mathrm{M}$, $\mathrm{RM}$ and short proximal section of $\mathrm{R}_{4+5}$ and $\mathrm{M}_{1+2}$ bare, other veins with dense macrotrichia; $R_{4+5}$ ending distal of $\mathrm{M}_{3+4}$ and proximal of $\mathrm{M}_{1+2}, \mathrm{FCu}$ slightly distal of RM. Legs. Fore tibia with straight spur c. $10 \mu \mathrm{m}$ long; combs of mid and hind tibiae separated with teeth c. $10 \mu \mathrm{m}$ (mid tibia) to $15 \mu \mathrm{m}$ long (hind tibia), each comb bearing spur, mid tibia with two spurs of equal length (c. $20 \mu \mathrm{m}$ ), hind tibia with one spur c. $25 \mu \mathrm{m}$ long and one only slightly longer than teeth of its comb; ta $a_{1}$ of $\mathrm{p}_{2}$ bearing 5 hook-shaped sensilla chaetica $(\mathrm{n}=1)$; length of leg segments and leg ratios in Table 2.

Hypopygium. Gonostylus $120 \mu \mathrm{m}$ long, regularly tapering to slender tip. Anal tergite with 5-6 long median setae and separated dark and wide bands of V-type, lateral teeth absent; anal point

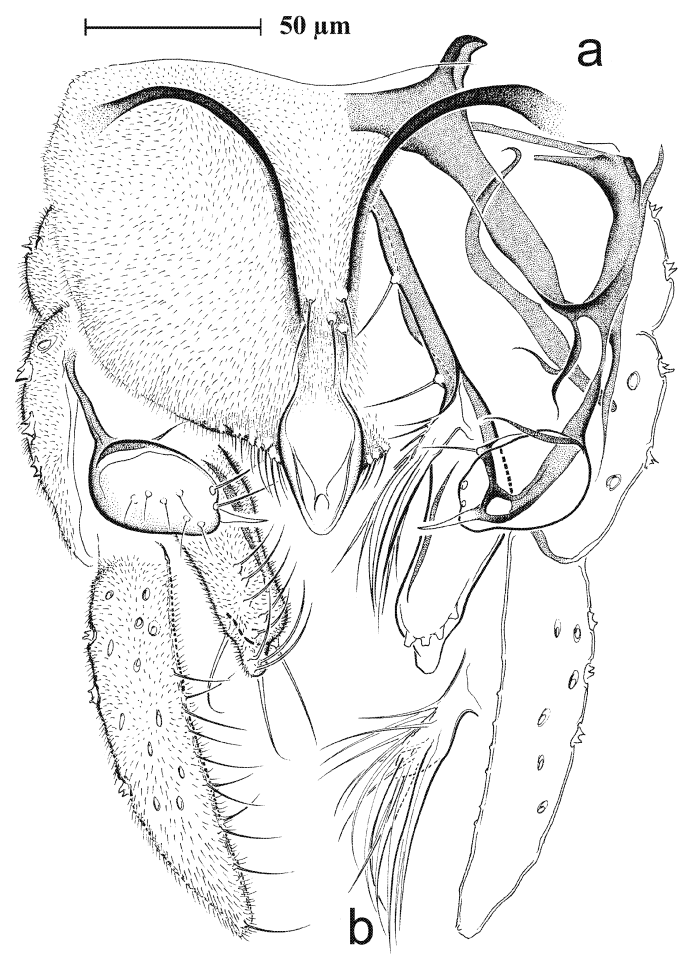

Fig. 2. Paratanytarsus paralaccophilus sp. n., male. a. Hypopygium. - b. Median volsella. 
short, with broadly rounded apex, flake-shaped crests arranged typically for Paratanytarsus and separated by subapical knob, 3-5 long lateral setae placed on each side of anal point. Superior volsella oval, slightly elongated and directed medially, with 5-6 dorsal setae, 2 setae in anteromedian position and single seta at base; digitus slender and sharply pointed, extending far beyond apex of superior volsella (Fig. 2a). Stem of median volsella 25-30 $\mu \mathrm{m}$ long, apically swollen, bearing dense setiform and 5-6 slender subuliform lamellae (Fig. 2b). Inferior volsella straight and stout, with thin but well pigmented dorsomedian ridge and bilobed apex bearing elongated protuberance (Fig. 2a).

\subsubsection{Type material}

Holotype. Male slide-mounted in Euparal: Finland, Inari distr., Sarmi area, Vanhapäänmorosto, c. $13 \mathrm{~km}$ west of the Russian border $\left(68^{\circ} 40^{\prime} \mathrm{N}\right.$ $28^{\circ} 17^{\prime} \mathrm{E}$ ), 14.VI.-10.VIII.2005, Malaise and emergence traps, leg. J. Salmela (DIZUG).

Paratypes. $2 \hat{\delta} \hat{\delta}$ as holotype slide-mounted in Canada balsam (1 DIZUG, 1 MIZPAS).

\subsubsection{Derivation of the name}

The specific name refers to Paratanytarsus laccophilus, the presumed closest relative of the new species.

\subsubsection{Discussion}

The adult male of Paratanytarsus paralaccophilus is very easily separable from all other species of the genus by characters in the male hypopygium. The oval, elongated and medially directed superior volsella, the slender and sharply pointed digitus, the long stem of the median volsella armed with subuliform lamellae and the bilobed inferior volsella with protuberance on its apex create the unique character combination. The closest relative, Paratanytarsus laccophilus, has a similar structure of the anal tergite including the anal point, the shape of the superior volsella and the digitus, as well as the inferior volsella divided into two lobes. However, a slender gonostylus, regularly tapering to its pointed apex in $P$. paralaccophilus as opposed to the apically abruptly narrowed gonostylus in $P$. laccophilus, is a reliable diagnostic character separating the two species. An additional feature that distinctly separates these species is the size and shape of the median volsella and its lamellae. Paratanytarsus laccophilus has a very short, medially directed stem of the median volsella bearing short foliate lamellae (Fig 10 in Reiss \& Säwedal 1981), while $P$. paralaccophilus has a longer posteromedially directed stem with long, subuliform lamellae (Fig. 2). Due to the latter character, $P$. paralaccophilus will key out to couplet 4 (penicillatus group) in the key to Paratanytarsus species groups by Cranston et al. (1989), and to the next couplet (laccophilus group) when the elongated lamellae are disregarded. The morphological features of $P$. paralaccophilus indicate that the penicillatus and laccophilus groups are closely related, but as a result of our discussion above, we would argue for a placement of $P$. paralaccophilus in the laccophilus species group.

Adult males of Paratanytarsus paralaccophilus were collected between mid-June and midAugust with the Malaise and emergence traps set at small spring brooks in a eutrophic swampy area in Finnish Lapland. They were collected together with Parapsectra chionophila (Edwards, 1933) and $P$. nana (Meigen, 1818), known as cold stenothermic inhabitants of springs, streams and moorland pools.

\subsection{Tanytarsus paraniger $\mathrm{sp} . \mathrm{n}$.}

\subsubsection{Diagnosis}

Adult male. Anal point with granulose apex, armed with spinulae and small dense tubercles placed between crests. Superior volsella robust, with large and strongly curved posterolateral corner, bearing a distinct hook-shaped ventral protuberance in posteromedian position; ventral surface of superior volsella wrinkled, posterior margin bare, only with a few fine tubercles.

\subsubsection{Description}

Adult male ( $\mathrm{n}=10$, unless otherwise stated). Wing length $2.31-2.91 \mathrm{~mm}(2.58, \mathrm{n}=7)$. Coloration. Antennal flagellum, halter and proximal 
Table 3. Length $(\mu \mathrm{m})$ of leg segments and leg ratios of male Tanytarsus paraniger sp. $\mathrm{n}$.

\begin{tabular}{lllllllll}
\hline & $\mathrm{fe}$ & $\mathrm{ti}$ & $\mathrm{ta}$ & $\mathrm{ta}$ & $\mathrm{ta}$ & $\mathrm{ta}_{2}$ & $\mathrm{ta}_{5}$ & $\mathrm{LR}$ \\
\hline $\mathrm{p}_{1}$ & $895-1095$ & $700-905$ & $980-1215$ & $535-660$ & $405-515$ & $265-355$ & $175-205$ & $1.32-1.50$ \\
& $(985, \mathrm{n}=8)$ & $(775, \mathrm{n}=8)$ & $(1100, \mathrm{n}=5)$ & $(605, \mathrm{n}=5)$ & $(475, \mathrm{n}=5)$ & $(325, \mathrm{n}=5)$ & $(190, \mathrm{n}=5)$ & $(1.42, \mathrm{n}=5)$ \\
$\mathrm{p}_{2}$ & $895-1065$ & $845-1020$ & $425-530$ & $295-345$ & $215-265$ & $155-200$ & $130-155$ & $0.49-0.52$ \\
& $(965, \mathrm{n}=6)$ & $(920, \mathrm{n}=6)$ & $(470, \mathrm{n}=6)$ & $(315, \mathrm{n}=6)$ & $(245, \mathrm{n}=6)$ & $(175, \mathrm{n}=6)$ & $(140, \mathrm{n}=6)$ & $(0.51, \mathrm{n}=6)$ \\
$\mathrm{p}_{3}$ & $1090-1310$ & $1080-1380$ & $720-865$ & $485-595$ & $375-485$ & $235-330$ & $160-190$ & $0.62-0.67$ \\
& $(1170, \mathrm{n}=6)$ & $(1205, \mathrm{n}=6)$ & $(775, \mathrm{n}=7)$ & $(535, \mathrm{n}=8)$ & $(425, \mathrm{n}=8)$ & $(275, \mathrm{n}=8)$ & $(175, \mathrm{n}=8)(0.64, \mathrm{n}=6)$ \\
\hline
\end{tabular}

abdominal segments olive brown, wing membrane pale, veins brownish, remaining parts of body brown to dark brown. Head. Antenna with 13 flagellomeres; AR 1.34-1.70 (1.44, $\mathrm{n}=6)$; frontal tubercles $8-20 \mu \mathrm{m}$ long, c.10 $\mu \mathrm{m}$ wide; length of palpomeres II-V $(\mu \mathrm{m}, \mathrm{n}=8)$ : $52-71$ (60), 119-151 (131), 123-167 (141), 159-214 (191); clypeus with 16-25 setae. Thorax chaetotaxy. Ac usually absent (a few dispersed acrostichals present in two examined specimens), Dc 9-15, Pa 1-2 (usually 1), Scts 8-14 (placed in regular row). Wing. Membrane covered with macrotrichia in cells $\mathrm{r}_{4+5}$ and $\mathrm{m}_{1+2}$, a few macrotrichia placed under RM and distal area of cell $\mathrm{m}_{3+4}$; veins $\mathrm{Sc}, \mathrm{M}, \mathrm{RM}, \mathrm{Cu}$, proximal half of $\mathrm{R}_{4+5}$, $\mathrm{M}_{1+2}$ and $\mathrm{Cu}_{1}$ bare, An usually with a few macrotrichia in proximal half or bare, other veins with macrotrichia; $\mathrm{R}_{4+5}$ ending well distal of $\mathrm{M}_{3+4}$ and slightly proximal of $\mathrm{M}_{1+2}, \mathrm{FCu}$ under or somewhat distal of RM. Legs. Fore tibia armed with single or two spurs (observed in specimens of two examined populations) - one spur curved and long $(30-35 \mu \mathrm{m})$ and one straight and slightly shorter $(25-30 \mu \mathrm{m})$ (Fig. 3g-h); combs of mid and hind tibiae separated with teeth $15 \mu \mathrm{m}$ (mid tibia) to $20 \mu \mathrm{m}$ long (hind tibia), each comb with spur 25-30 $\mu \mathrm{m}$ (mid tibia) to $35-45 \mu \mathrm{m}$ long (hind tibia); ta ${ }_{1}$ of $\mathrm{p}_{2}$ bearing 4-8 hook-shaped sensilla chaetica; length of leg segments and leg ratios in Table 3.

Hypopygium. Gonostylus 180-200 $\mu \mathrm{m}$ long, swollen and somewhat flattened in proximal half. Anal tergite without median setae, with extensive microtrichia-free area surrounding elevated hump placed in median position. Darkly pigmented anal tergite bands of V-type. Lateral teeth weak or absent. Anal point variable in shape, usually stout with broadly rounded granulose apex (Fig. 3b-c), sometimes slender tapering to nar- row tip (Fig. 3a), armed with 2-6 spinulae and small dense tubercles placed between well developed parallel crests; field of long microtrichia at base and 7-12 lateral setae on each side of anal point (Figs $3 \mathrm{a}-\mathrm{c}, 4 \mathrm{a}$ ). Superior volsella robust, with large strongly curved posterolateral corner, bearing a distinct hook-shaped ventral protuberance in posteromedian position; ventral surface of superior volsella wrinkled, posterior margin

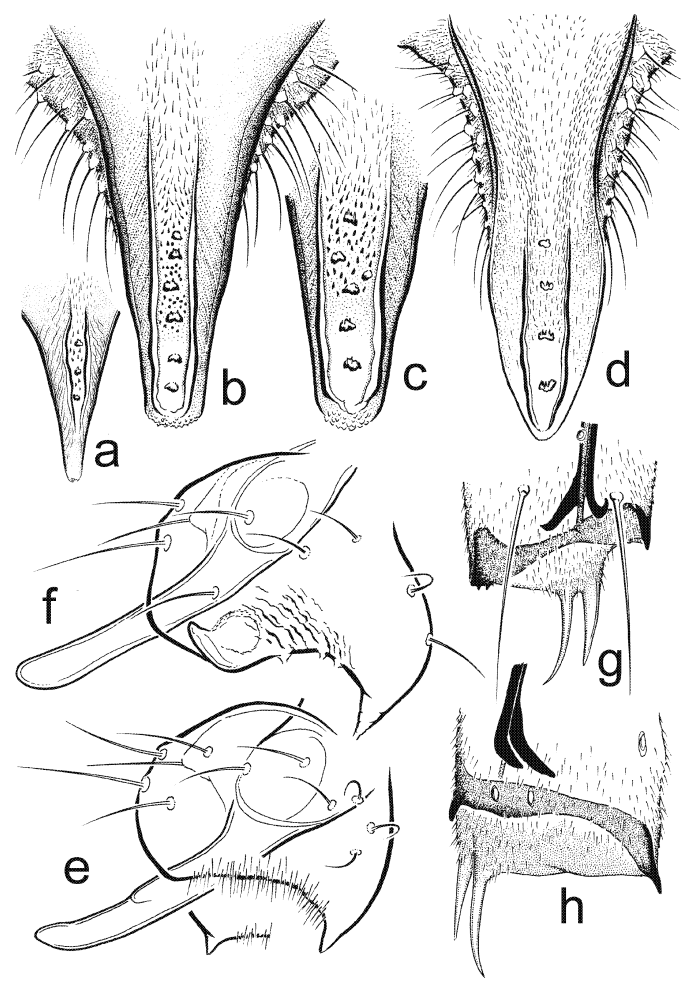

Fig. 3. Tanytarsus paraniger sp. n., male (a-c, $f-h), T$. niger Andersen, 1937, male (d, e). - a-d. Anal point. e-f. Superior volsella and digitus. $-g-h$. Spurs of fore tibia in dorsal view (g) and lateral view (h). 


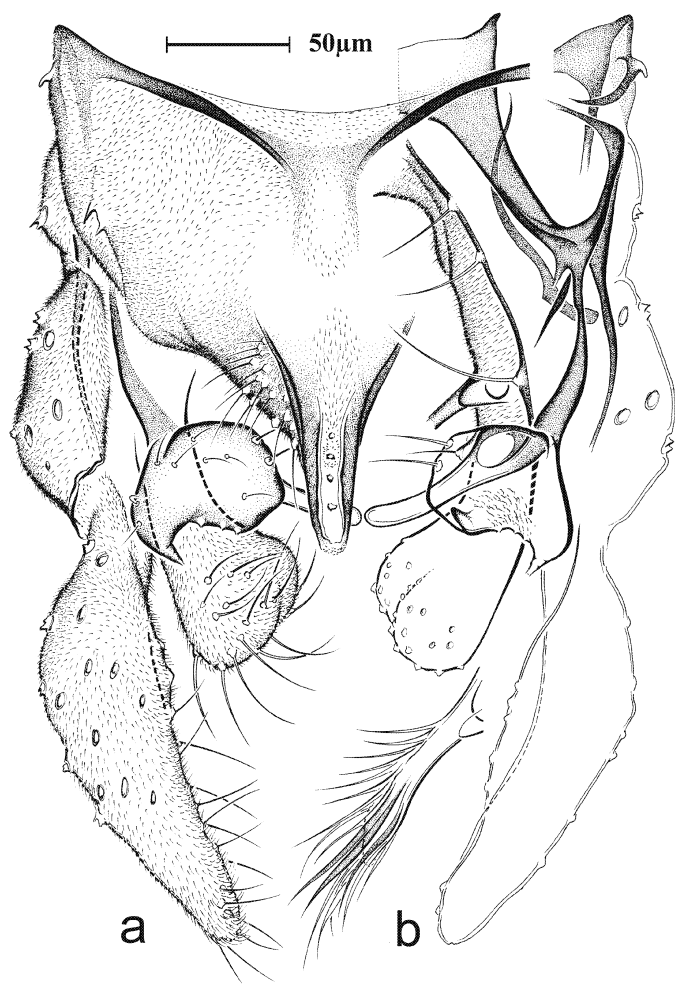

Fig. 4. Tanytarsus paraniger sp. n., male. - a. Hypopygium. - b. Median volsella.

bare, with a few fine tubercles; 2 anterolateral, 1 ventromedian and 6-12 dorsolateral setae placed on superior volsella; digitus long, apically rounded, extending far beyond apex of superior volsella (Figs 3f, 4a). Stem of median volsella 45-50 $\mu \mathrm{m}$ long, straight, bearing dense setiform and subuliform lamellae (Fig. 4b). Inferior volsella robust, with bilobed, swollen and widely rounded distal part (Fig. 4a).

\subsubsection{Type material}

Holotype. Male slide-mounted in Canada balsam: Finland, Inari distr., River Akujoki nr. Ivalo (684’N 27³8’E), 01.-03.VI.1979, leg. R. Palomäki (DIZUG).

Paratypes. 3 ôे: as holotype (2 DIZUG, 1 MIZPAS); 3 đơ: Finland, Saarijärvi nr. Jyväskylä, Pyhä-Häkki, Lake Kultalampi (62 $51^{\circ} \mathrm{N}$ 2522'E), 22.V.1978 (2 DIZUG, 1 MIZPAS); 3

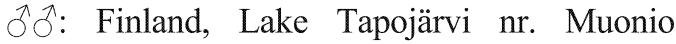
(67³0’N 2339'E), 24.VI.1982, netting (DIZUG), leg. L. Paasivirta.

\subsubsection{Derivation of the name}

The name refers to Tanytarsus niger, the presumed closest relative of the new species.

\subsubsection{Discussion}

Tanytarsus paraniger fits well in the norvegicus group as diagnosed by Reiss and Fittkau (1971). The new species has a broadened and flattened gonostylus, an anal tergite without median setae, with a darkly pigmented elevated hump in the median position, an anal point with a field of anteriorly directed microtrichia, a superior volsella with a large posterolateral corner, a stout digitus and a median volsella bearing subuliform lamellae.

Tanytarsus paraniger is very similar to $T$. $n i$ ger and most likely has been so far confused with it. The character that best separates $T$. paraniger from $T$. niger is a hook-shaped posteromedian protuberance placed on the wrinkled ventral surface of the superior volsella as well as the presence of fine tubercles on the posterior margin of this appendage (Figs 3f, 4a). These structures are known exclusively from $T$. paraniger. In addition, the anal point of the new species is armed with small tubercles placed between the crests and has a granulose, usually broadly rounded apex (Figs 3a-c, 4a). These characters are absent in $T$. niger, in which the hypopygial anal point is lanceolate and posterior margin of the superior volsella is covered by dense microtrichia (Fig. $3 \mathrm{~d}-\mathrm{e})$. Another unusual character found in $T$. paraniger is a double spur on the fore tibia (Fig. $3 g-h)$, this structure, however, has not been observed in all the specimens examined.

$T$. paraniger was sampled in lakes and in a lenient river. The new species seems to prefer mesotrophic habitats, both lentic and lotic, whereas $T$. niger is known from eutrophic lentic habitats. Both are spring univoltine species.

Acknowledgements. We thank Jukka Salmela and Risto Palomäki for collecting the material, anonymous reviewers for comments on earlier version of the manuscript, and Elisabeth Stur and Torbjørn Ekrem for inspiring discussions on the taxonomy of the tribe Tanytarsini. Special thanks to Jari Tuiskunen for making his unpublished descriptions and notes on systematics of the tribe available to us. 


\section{References}

Cranston, P.S., Dillon, M.E., Pinder, L.C.V. \& Reiss, F. 1989: 10. The adult males of Chironominae (Diptera: Chironomidae) of the Holarctic region - Keys and diagnoses. - Entomol. Scand., suppl. 34: 353-502.

Giłka, W. 2001: A description of Micropsectra rilensis sp. n. (Diptera: Chironomidae) with a review of Bulgarian Tanytarsini. - Polskie Pismo Entomol. 70: 65-72.

Giłka, W. 2005: A systematic review of European Stempellina Thienemann et Bause (Diptera: Chironomidae) with description of a new species from Fennoscandia. - Ann. Zool. 55: 413-419.

Giłka, W. \& Abramczuk, Ł. 2006: Micropsectra davigra sp. n. from the Tatra Mountains - a contribution to the systematics of the Micropsectra attenuata species group (Diptera: Chironomidae). - Polskie Pismo Entomol. 75: 39-44.

Giłka, W. \& Paasivirta, L. 2007: Two new species in the genus Tanytarsus van der Wulp (Diptera: Chironomidae) from Fennoscandia. - In: Andersen, T. (ed.), Contributions to the Systematics and Ecology of Aquatic Diptera - A Tribute to Ole A. Sæther, pp. 107113. The Caddish Press, Columbus, Ohio.

Reiss, F. \& Fittkau, E.J. 1971: Taxonomie und Ökologie europäisch verbreiteter Tanytarsus-Arten (Chironomidae, Diptera). - Arch. Hydrobiol, suppl. 40: 75200.

Reiss, F. \& Säwedal, L. 1981: Key to males and pupae of Palearctic (exl. Japan) Paratanytarsus Thienemann, Bause 1913, n. comb., with description of three new species (Diptera, Chironomidae). - Entomol. Scand., suppl. 15: 73-104.

Sæther, O.A. 1980: Glossary of chironomid morphology terminology (Diptera: Chironomidae). — Entomol. Scand., suppl. 14: 1-51.

Sæther, O.A. \& Spies, M. 2004: Chironomidae. In: Fauna Europaea Service, Fauna Europaea version 1.1. Internet database available online: www.faunaeur.org (date of access: $10^{\text {th }}$ Jan. 2007).

Säwedal, L. 1976: Revision of the notescens-group of the genus Micropsectra Kieffer, 1909 (Diptera: Chironomidae). - Entomol. Scand. 7: 109-144.

Säwedal, L. 1981: Micropsectra tori n. sp. from Greenland, with notes on the recurvata-group (Diptera: Chironomidae). - Entomol. Scand 12: 27-30.

Stur, E. \& Ekrem, T. 2006: A revision of West Palaearctic species of the Micropsectra atrofasciata species group (Diptera: Chironomidae). — Zool. J. Linn. Soc. 146: 165-225. 